\title{
Determination of Conversion Constant between Lagos Datum and Niger Delta Mean Lower Low Water Datum and their Horizontal and Vertical Accuracy Standards using GNSS Observations
}

\author{
${ }^{1}$ Ehigiator, M. O. and ${ }^{2}$ Oladosu, S. O. \\ ${ }^{1}$ Department of Basic Sciences (Geophysics option), Benson Idahosa University, Benin City, Edo State, Nigeria \\ ${ }^{2}$ Department of Geomatics, Faculty of Environmental Sciences, University of Benin, Benin City, Edo State, \\ Nigeria \\ Corresponding Author: *mehigiator@biu.edu.ng
}

\begin{abstract}
With the use of Global Navigation Satellite System (GNSS) technology, it is now possible to determine the position of points in 3D coordinates systems. Lagos datum is the most common Mean Sea Level used in most parts of Nigeria. In Niger Delta, for instance Warri and its environs, the most commonly used datum for height determination is the Mean Lower Low Water Datum. It then becomes necessary to determine a constant factor for conversion between the two datum when the need arises as both are often encountered during Geomatics Engineering field operations. In this paper, the constant to be applied in converting between both datum was determined. The constant was found to be $17.79 \mathrm{~m}$. The horizontal and vertical accuracy standard was also determined as well as the stack maps.
\end{abstract}

Keywords: GNSS, Accuracy Standard, Observation, Datum, Horizontal, Static Technique

\subsection{Introduction}

The proliferation of Global Navigation Satellite System (GNSS) receivers in Nigeria has drastically brought a significant reduction in the rigour posed by using conventional survey equipment and techniques in the establishment and densification of control points of high order accuracy standard for mapping and Geographical Information System (GIS) purposes. Not only does GNSS have many advantages over the conventional methods, it also saves time, efforts and can cover large area within the shortest possible time.

GNSS receivers are available in different categories. The three categories according to Pete and Krista (2012) are survey-grade, consumer's grade and mapping grade. Each grade as noted by them can provide as follows: survey-grade receiver gives sub-centimetres static horizontal position accuracy in open air but sub-meters accuracy in or near forest area (Pirti, 2008); mapping-grade receiver may be able to give sub-meter in static horizontal position accuracy, but usually $2-5 \mathrm{~m}$ in or near forest area; while the consumer-grade gives the lowest. In terms of open air, GNSS can give static horizontal accuracy of up to $5 \mathrm{~m}$ while in forested area it ranges between $5-25 \mathrm{~m}$. GNSS is able to measure ranges between points up to $20-30 \mathrm{~km}$ or more. The differential tropospheric separation is usually ignored for horizontal separations less than approximately $30 \mathrm{~km}$; however, differences in height should be modelled since horizontal gives higher accuracy than vertical. The differential ionospheric separation is usually ignored for separations of less than $30 \mathrm{~km}$, depending on ionospheric conditions. Due to ionospheric uncertainty, it is better to calibrate for the ionosphere using dual-frequency receivers for distances greater than a few km (Geoffrey, 1997).

Sources of errors in GNSS surveying include but are not limited to: 
The multipath effect, which is caused by reflection of satellite signals (radio waves) on objects in contact. For GPS signals this effect mainly appears in the neighbourhood of large buildings, foliage, terrain, vehicle structure and so on.

(ii) Atmospheric (tropospheric and Ionospheric) error: Since atmosphere is varied at different places at different times, it causes a delay not possible to be accurately compensated for. Also, radio signals which travel at the speed of light are slower in ionosphere. To mitigate this, inverse square law is applied and the waves are slowed down inversely proportional to the square of their frequency $\left(1 / \mathrm{f}^{2}\right)$ while passing the ionosphere (the ionosphere delays the code but advances the phase). For troposphere, the reasons for the refraction are different concentrations of water vapours, caused by different weather conditions. The error caused by tropospheric effect is smaller than that of ionospheric effect, but cannot be eliminated by calculation. It can only be approximated for by a general calculation model.

(iii) Receiver Error: Since the receivers are also not perfect, they can introduce their own errors which usually occur from their clocks or internal noise. Despite the synchronization of the receiver clock with the satellite time during the position determination, the remaining inaccuracy of the time still leads to an error of about $2 \mathrm{~m}$ in the position determination. Rounding and calculation errors of the receiver sum up approximately to $1 \mathrm{~m}$ (CED, 2012; Ehigiator et al., 2017), in stand-alone positioning.

Lagos 1955 as reported by (Badejo et al., 2014) is a vertical datum first defined in 1955 and is suitable for use in Nigeria. Lagos 1955 origin is Mean Sea Level at Lagos, 1912-1928. Lagos 1955 is a vertical datum for Geodetic survey, topographic mapping and engineering survey. It was defined by information from (Ebong et al. and AVN International, 1991; Uzodinma, 2005). The Lagos Datum is $2.8310 \mathrm{~m}$ above Mean Sea Level (British Oceanic Data Centre, 2011). The Lagos datum is the height commonly adopted in Nigeria mapping system. This is not true for areas in Niger Delta where oil and Gas are produced. Height determination is usually referenced to Low Low Water (LLW).

Warri Mean Lower Low Water (WMLLW) is the average of all the lower low water elevations (heights) observed over the official segments over which tidal observations has been made and reduced by taking the mean value. These levels has the maximum high tide recorded in the tide tables for Warri which is of a maximum height of $1.9 \mathrm{~m}$ and a minimum height of $0.1 \mathrm{~m}$ (Tides and Solunar Charts, 2013). This study was aimed at establishing controls at Warri for mapping and prospecting purposes. Two base stations were set up in Benin on XSU92 and BEM_1000 which are government controls while four other points were coordinated in Warri, Delta State.

\subsection{Observation times and baseline lengths}

The observation time required for an accurate result in post processing depends on several factors such as baseline length, number of satellites, satellite geometry (GDOP) and ionosphere (Leica Geosystems User's Manual, 2000). Ionospheric disturbances vary with time, day, night, month, year and position on earth's surface. Generally, the larger the constellation of satellites, the better the available geometry, the lower the positioning dilution of precision (PDOP), and the shorter the length of the session needed to achieve the required accuracy (GPS and GNSS for Geospatial Professionals, 2015). With static observation method, four (4) or more satellites with a baseline length of $15-30 \mathrm{~km}$ should be observed for $1-2 \mathrm{hrs}$ by day and $1 \mathrm{hr}$ at night; while four (4) or more satellites with a baseline length of over $30 \mathrm{~km}$ should be observed for $2-3 \mathrm{hrs}$ by day and $2 \mathrm{hr}$ at night. RICS (2010) also noted in the same vein the following accuracy conditions for GNSS survey; Dual-frequency receivers $\mathrm{H}-5 \mathrm{~mm}+1 \mathrm{ppm}, \mathrm{V}-10 \mathrm{~mm}+1 \mathrm{ppm}$, Baseline $20 \mathrm{~km}$ for at least $1 \mathrm{hr}, 30 \mathrm{~km}$ for at least $2 \mathrm{hrs}, 50 \mathrm{~km}$ for at least $4 \mathrm{hrs}, 100 \mathrm{~km}$ for at least $6 \mathrm{hrs}$. The observation times for the baselines are as presented in Table 1 while baseline lengths in kilometres are presented in column 3 of Table 3.

This work commenced on the 10th of October, 2017 and ended the same day. Observers were positioned at each stations and communication to start the equipment were made through hand set 
(communication gadgets) as soon as responses from all stations were perfected, data acquisition commenced immediately.

Table 1: Station Location and Occupation Time

\begin{tabular}{|c|c|c|c|c|c|c|}
\hline Control Stn_ID & Status & Occupation Time & Start Time & Stop Time & $\begin{array}{c}\text { No of } \\
\text { satellites } \\
\text { acquired }\end{array}$ & Location \\
\hline BEM_1000 & Known & 6hrs:14mins & $08: 32 \mathrm{am}$ & $14.46 \mathrm{pm}$ & 12 & Benin \\
\hline GPS-ITER_01 & Unknown & $4 \mathrm{hr}: 47 \mathrm{mins}$ & $10: 35 \mathrm{am}$ & $13: 22 \mathrm{pm}$ & 11 & Warri \\
\hline NP-WW01 & Unknown & $5 \mathrm{hr}: 47 \mathrm{mins}$ & $09: 55 \mathrm{am}$ & $13: 42 \mathrm{pm}$ & 09 & Warri \\
\hline NP-WW02 & Unknown & $5 \mathrm{hr}: 51 \mathrm{mins}$ & $09: 49 \mathrm{am}$ & $13: 40 \mathrm{pm}$ & 08 & Warri \\
\hline NP-WW03 & Unknown & $4 \mathrm{hrs}: 08 \mathrm{mins}$ & $10: 59 \mathrm{am}$ & $14: 08 \mathrm{pm}$ & 10 & Warri \\
\hline XSU92 & Known & $6 \mathrm{hrs}: 12 \mathrm{mins}$ & $08: 35 \mathrm{am}$ & $14: 12 \mathrm{pm}$ & 12 & Benin \\
\hline
\end{tabular}

Table 1, shows the control station locations and IDs, their status at the time the project was carried out and the occupation time spent on each station for which the receivers to acquire spatial data.

\subsection{Network design}

The network design goes a long way in affecting the results that are obtained from the survey work. Therefore, its design must take into account the following objectives which were strictly adhered to in this work. The nature and characteristics of the project site made it necessary to establish the controls above flood plain as it is close to an adjoining river. The lengths of each base line have been included in Table 3. Clearance of least $250 \mathrm{~m}$ away from a radio transmitter or mobile phone tower was carefully observed during the establishment of the controls and subsequent field work to prevent interference, and finally multipath inducing objects like tall buildings, and large bill boards were avoided in the course of survey execution.

The design of the network took into consideration the listed factors above, which are very crucial to the integrity of data acquired. Figure 1 show the diagram of the designed network. The network was designed in such a way as to avoid both natural and artificial disturbances on the site.

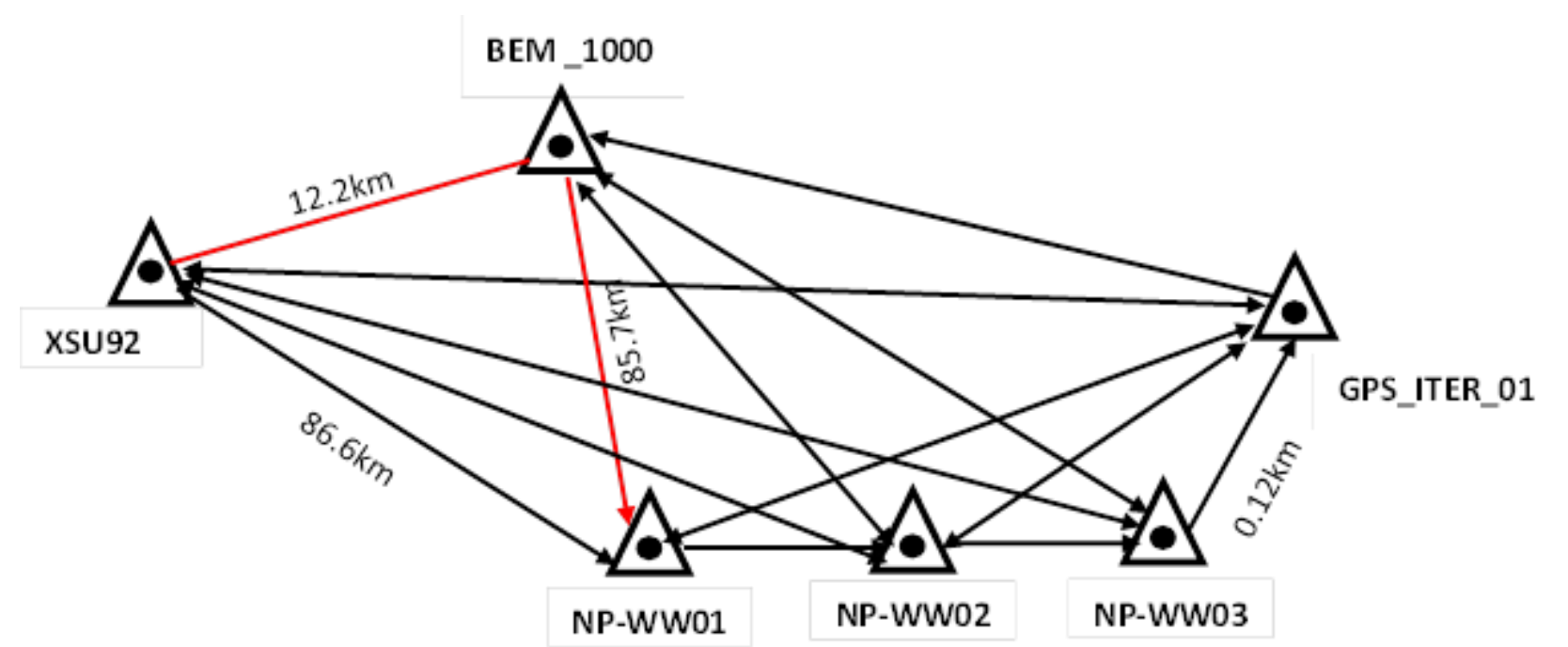

Figure 1: Network design diagram

\subsection{Materials and Methods}

i. 1 x Hi-Target V30 50 Dual Frequency GNSS (Global Navigation Satellite System) 'Base Station' receiver

ii. 5 x Hi-Target V30 50 Dual Frequency GNSS (Global Navigation Satellite System) 'Rover' receiver

iii. $1 \mathrm{x}$ Data Processing Computer and Accessories 
On the 15th of October, 2017 data were collected between the hours of 08:32am Nigerian time and $14: 12 \mathrm{pm}$. Instruction was passed to the observers to watch out for when the value of standard deviation of acquired satellite values as read from the data logger is reduced to barest minimum before taking measurement.

Static technique was adopted in the process of data acquisition in which the (receivers) are set on known base stations and the rover (receiver) on the unknown stations both acquiring data simultaneously with regular communication with each other. In static technique post processing is required unlike in RTK technique.

\subsection{Data acquisition}

GNSS observations were carried out using two existing (Government) GNSS $1^{\text {st }}$ order control stations in Benin City. In-situ and stability tests were performed on the two GNSS control stations i.e. BEM_1000 and XSU92 used for this investigation. Hi-Target GNSS receiver was setup on XSU92 and BEM_1000 and the data collected was processed while XSU92 was held fixed. The coordinate of XSU92 obtained was compared with the given coordinates; the results are presented as shown in Table 2 below.

Table 2: Integrity check on BEM_1000 and XSU92, $1^{\text {st }}$ order controls

\begin{tabular}{|l|r|r|l|l|l|l|l|}
\hline Station & \multicolumn{3}{|c|}{ Given Coordinates } & \multicolumn{3}{c|}{ Obtained Coordinates } & Remark \\
Name & $\mathrm{N}(\mathrm{m})$ & $\mathrm{E}(\mathrm{m})$ & $\mathrm{H}(\mathrm{m})$ & $\mathrm{N}(\mathrm{m})$ & $\mathrm{H}(\mathrm{m})$ & \\
\hline XSU92 & 257998.9930 & 357763.3315 & 103.9247 & 257999.2512 & 357763.3333 & 86.1242 & ok \\
\hline BEM_1000 & 244420.3051 & 356733.3788 & 54.3573 & 244420.5072 & 356733.3593 & 36.5656 & ok \\
\hline
\end{tabular}

In Table 2, the check on the integrity of the two controls was performed after centering and levelling of the instruments. The results showed that horizontal coordinate values are more accurate than vertical coordinate values.

\subsection{Data post-processing}

The collected survey data in static mode saved in the instrument memory was downloaded to PC with post-processing software (Hi-target Geomatics Office) which was then processed accordingly.

\subsection{Datum transformation}

The term datum is used to describe the reference frame for geodetic computation. The position of a point on the earth surface can be given either in terms of $(\varphi, \kappa, h)$ or $(X, Y, Z)$ coordinates systems. Whichever system is used has an origin and a relationship for transformation to other systems. The transformation from $(\varphi, \kappa, h)$ system to $(X, Y, Z)$ system can be achieved using the following relationship (Georgiadou et al., 2001).

The formula to perform the Molodensky Abridge Model for transforming WGS84 to the equivalent Minna datum Geographical coordinates read thus:

$$
\begin{aligned}
& \Delta \varphi^{\prime \prime}=\left[-t_{x} \operatorname{Sin} \varphi \operatorname{Cos} \lambda-t_{y} \operatorname{Sin} \varphi \lambda+t_{z} \operatorname{Cos} \varphi+(a \Delta f+f \Delta a) \operatorname{Sin} 2 \varphi /\left(M \operatorname{Sinl} 1^{\prime \prime}\right)\right] \\
& \Delta \lambda^{\prime \prime}=\left[-t_{x} \operatorname{Sin} \lambda+t_{y} \operatorname{Cos} \lambda\right] /\left(V \operatorname{Cos} \varphi \operatorname{Sin} 1^{\prime \prime}\right] \\
& \Delta \varphi^{\prime \prime}=\left[-t_{x} \operatorname{Sin} \varphi \operatorname{Cos} \lambda-t_{y} \operatorname{Sin} \varphi \lambda+t_{z} \operatorname{Cos} \varphi+(a \Delta f+f \Delta a) \operatorname{Sin}^{2} \varphi /\left(M \operatorname{Sin} l^{\prime \prime}\right)\right] \\
& V_{(\varphi)}=\frac{a_{L}}{\left(1-e^{2} \operatorname{Sin}^{2} \varphi\right)^{\frac{1}{2}}}, M_{(\varphi)}=\frac{a_{L}\left(1-e^{2}\right)}{\left(1-e^{2} \operatorname{Sin}^{2} \varphi\right)^{\frac{3}{2}}}
\end{aligned}
$$

where:

$t x, t y, t z \quad$ Translations between both datum (in geocentric coordinates) 
$\varphi, \lambda, h \quad$ Geodetic co-ordinates of the local geodetic system ellipsoid

$\Delta \varphi, \Delta \lambda, \Delta h \quad$ Corrections to transform local datum co-ordinates to WGS84 $\varphi, \lambda, h$

$\Delta \mathrm{X}, \Delta \mathrm{Y}, \Delta \mathrm{Z} \quad$ Corrections to transform local datum co-ordinates to WGS84 $X, Y, Z$

$\Delta a, \Delta f$

(WGS84 minus local) semi-major axis and flattening respectively

$a$

Semi-major axis of the local geodetic system ellipsoid

$f \quad$ Flattening of the local geodetic system ellipsoid

$\mathbf{M}_{(\varphi)} \quad$ Radius of curvature in the meridian

$\mathrm{V}_{(\varphi)}$

Prime vertical radius of curvature

The datum shift parameters derived by Shell Petroleum Development Company, (2010), are presented thus: Datum Shift Parameters from WGS84 to Minna datum geographical coordinates are:

$t_{x}=$ plus 111.916
$a_{L}=6378249.145$

$$
\begin{aligned}
& t_{y}=\text { plus } 87.852 \\
& { }_{L}=1 / 293.465
\end{aligned}
$$$$
t_{z}=\text { minus } 114.499
$$$$
\Delta f=\text { minus } 0.54750714
$$

Mathematically transformation from one datum to another can be realized by relating the geographic coordinates $(\varphi, \kappa, h)$ of both datum systems directly or indirectly by relating the geocentric coordinates $(X, Y, Z)$ of the datum.

The transformation from $(\varphi, K, h)$ system to $(X, Y, Z)$ system can be achieved using the following relationship by SNZGD (2000):

$$
\left.\begin{array}{l}
X=[N+h] \cos \phi \cos \lambda \\
Y=[N+h] \cos \phi \sin \lambda \\
Z=\left[N\left(1-e^{2}\right)+h\right] \sin \phi
\end{array}\right\}
$$

where:

$N \quad$ Radius vector of the prime vertical

$h \quad$ Point above ellipsoid

$e \quad$ Eccentricity.

$N$ and $e$ are given by:

$$
\left.\begin{array}{l}
e^{2}=2 f-f^{2} \\
N=\frac{a}{\left(1-e^{2} \sin ^{2} \phi\right)^{1 / 2}}
\end{array}\right\}
$$

Where:

$a \quad$ Major axis of the earth, and

$f \quad$ Flattening of the reference ellipsoid.

For WGS84, $a=6,378,137 \mathrm{~m}, f=1 / 298.257223563=0.003352810665$.

These formulas used by the SNZGD (2000) can be used to convert the Cartesian coordinates $(X, Y, Z)$ to the geographic coordinates $(\varphi, \kappa, h)$ as follows:

$$
\left.\begin{array}{l}
\tan \lambda=Y / X \\
\tan \phi=\frac{Z(1-f)+e^{2} a \sin ^{3} \mu}{(1-f)\left(p-e^{2} a \cos ^{3} \mu\right.} \\
h=p \cos \phi+Z \sin \phi-a \sqrt{1-e^{2} \sin ^{2} \phi}
\end{array}\right\}
$$

where $a$ and $f$ are obtained from the ellipsoid under consideration for the geodetic datum respectively. 


$$
\left.\begin{array}{c}
p=\sqrt{X^{2}+Y^{2}} \\
r=p^{2}+Z^{2} \\
\tan \mu=\frac{Z}{p}\left[(1-f)+\frac{e^{2} a}{r}\right]
\end{array}\right\}
$$

\subsection{Carrier phase method}

The carrier phase model is presented in equation (5) as follows: Michael, (2005).

$$
\varphi(t)=\frac{1}{\lambda}[r(t)-I+T]+f\left(\delta t_{U}-\delta t^{S}\right)+N+\varepsilon_{\varphi}
$$

where:

$\varphi \quad$ Partial carrier phase cycle measured by the receiver

$\lambda \quad$ Wavelength

$f \quad$ Carrier frequency

$r \quad$ Geometric range between the receiver and the satellite

I Ionospheric advance

$T \quad$ Tropospheric delay, which are all expressed in units of meters.

$\delta t_{u}$ and $\delta t^{s}$, are the receiver and satellite clock biases respectively, which are expressed in units of seconds.

$N \quad$ Integer ambiguity, which is the total number of full cycles between the receiver and the satellite. The integer ambiguity cannot be measured and has to be estimated, but the integers remain constant as long as the carrier tracking loop maintains lock (Michael, 2005).

\subsubsection{Relative positioning using carrier phase}

The single difference for two receivers simultaneously collected data from one satellite is presented in equations (6) and (7). The differences between equations (6) and (7) eliminate Receiver clock error $\left(\delta t_{u}\right)$

$\varphi_{u}{ }^{k}(t)=\frac{1}{\lambda}\left[r_{u}{ }^{k}(t)-I_{u}{ }^{k}+T_{u}{ }^{k}\right]+f\left(\delta t_{u}-\delta t^{k}\right)+N+\varepsilon_{\varphi, u}{ }^{k}$

Similarly, the same expression can be written for the stationary reference receiver as:

$\varphi_{r}^{k}(t)=\frac{1}{\lambda}\left[r_{r}{ }^{k}(t)-I_{r}{ }^{k}+T_{r}{ }^{k}\right]+f\left(\delta t_{r}-\delta t^{k}\right)+N+\varepsilon_{\varphi, r}^{k}$

\subsubsection{Double difference}

The double and triple difference can be used to overcome integer ambiguity and clock bias problems inherent in single difference method. To eliminate the satellite clock bias term, two single difference equations can be subtracted to yield the double difference equation. This involves making use of two satellites (Michael, 2005).

$$
\begin{aligned}
\varphi_{u r}^{k l} & =\left(\varphi_{u}^{k}-\varphi_{r}^{k}\right)-\left(\varphi_{u}^{l}-\varphi_{r}^{l}\right) \\
\varphi_{u r}^{k l} & =\varphi_{u r}^{k}-\varphi_{u r}^{l} \\
\varphi_{u r}^{k l} & =\frac{1}{\lambda}\left(r_{u r}^{k}-r_{u r}^{k}\right)+f\left(\delta t_{u r}-\delta t_{u r}\right)+\left(N_{u r}^{k}-N_{u r}^{l}\right)+\left(\varepsilon_{u r}^{k}-\varepsilon_{u r}^{l}\right) \\
\varphi_{u r}^{k l} & =\frac{1}{\lambda}\left(r_{u r}^{k l}\right)+N_{u r}^{k l}+\varepsilon_{u r}^{k l}
\end{aligned}
$$


From equation (10), the satellite clock bias terms cancel out which reduces the number of unknowns to the 3 position coordinates and $(K-1)$ integer unknowns, where $K$ is the number of satellites. The relative position vector can be formed using the difference of the distance from the receivers to the satellites, $r_{u r}^{k}$ and $r_{u r}^{l}$, and the unit vectors in the direction of the $k^{\text {th }}$ and $l^{t h}$ satellites.

\subsubsection{Geometry of multiple receivers}

The geometry of the multiple receivers has been explained by Michael (2005), which has been employed in this work. If (XSU92) which is the base station is represented by A and any other point in the network as presented in Figure 1 as B, or $\mathrm{C}$ and subsequent point $\mathrm{D}$ or more points. Equation (12) shows a case of using one roaming receiver for double difference relative positioning. To start with, receiver $\mathrm{A}$ is the base station receiver, receiver $\mathrm{B}$ and $\mathrm{C}$ are the roaming receivers, and point $\mathrm{D}$ is a point in space whose position is to be determined.

$\lambda \varphi_{A B}=G_{A B} \vec{X}_{A B}+\lambda N_{A B}$

Where: $G_{A B}=\left[\begin{array}{c}-\left(1_{A}^{2}-1_{A}^{1}\right)^{T} \\ -\left(1_{A}^{3}-1_{A}^{1}\right)^{T} \\ \vdots \\ -\left(1_{A}^{K_{A B}}-1_{A}^{1}\right)^{T}\end{array}\right]$

For more receivers, Equation (13) can be used to determine the new position.

$$
\left[\begin{array}{c}
\lambda \varphi_{A B} \\
\lambda \varphi_{A C} \\
\vec{X}_{C B}
\end{array}\right]=\left[\begin{array}{cccccc} 
& G_{A B} & & & 0 \\
& 0 & & & G_{A C} & \\
1 & 0 & 0 & -1 & 0 & 0 \\
0 & 1 & 0 & 0 & -1 & 0 \\
0 & 0 & 1 & 0 & 0 & -1
\end{array}\right] *\left[\begin{array}{c}
\vec{X}_{A B} \\
\vec{X}_{A C}
\end{array}\right]+\lambda\left[\begin{array}{c}
N_{A B} \\
N_{A C} \\
0 \\
0 \\
0
\end{array}\right]
$$

where $\varphi_{A B}$ is a $\left(K_{A B}-1\right) \times 1$ vector in which $K_{A B}$ is the number of satellites that are common between receiver $\mathrm{A}$ and $\mathrm{B}, \varphi_{A C}$ is an $\left(K_{A C}-1\right) \times 1$ vector in which $K_{A C}$ is the number of satellites that are common between receiver $\mathrm{A}$ and $\mathrm{C}$, and $\vec{X}_{C B}$ is a $3 \times 1$ vector. This yields a total possible number of equations of $\left(K_{A B}-1\right)+\left(K_{A C}-1\right)+3$. The vectors $\vec{X}_{A B}$ and $\vec{X}_{A C}$ are also $3 \times 1$ and therefore, there are 6 unknowns which correspond to the receivers' positions. Therefore, the number of satellites that are necessary between receiver B and $\mathrm{C}$ are $K_{A B}+K_{A C} \geq 5$.

$$
\lambda\left[\begin{array}{c}
\varphi_{A B} \\
\varphi_{A C}
\end{array}\right]=\left[\begin{array}{c}
G_{A B} \\
G_{A C}
\end{array}\right] \vec{X}_{A B}+\lambda\left[\begin{array}{l}
N_{A B} \\
N_{A C}
\end{array}\right]+\left[\begin{array}{c}
0 \\
-G_{A C}
\end{array}\right] \vec{X}_{C B}
$$

Equation (14) represents the double difference where the constraint of knowing the vector between the two roaming receivers has been imposed by augmenting the measurements from the additional roaming receiver. For the two roaming receivers with the constraint of knowing the displacement vector $\vec{X}_{C B}$ is a different manner in which it uses the fact that $\vec{X}_{A C}=\vec{X}_{A B}-\vec{X}_{C B}$. The estimated location $\vec{X}_{A B}$ can be transformed into any point $\mathrm{D}$ in space as long as the vector from $\mathrm{D}$ to $\mathrm{B}$ is known. Equation (16) shows the transformation.

$$
\vec{X}_{A D}=\vec{X}_{A B}-\vec{X}_{D B}
$$




$$
\lambda\left[\begin{array}{l}
\varphi_{A B} \\
\varphi_{A C}
\end{array}\right]=\left[\begin{array}{l}
G_{A B} \\
G_{A C}
\end{array}\right] \vec{X}_{A D}+\lambda\left[\begin{array}{l}
N_{A B} \\
N_{A C}
\end{array}\right]+\left[\begin{array}{cc}
0 & -G_{A B} \\
-G_{A C} & -G_{A C}
\end{array}\right] *\left[\begin{array}{l}
\vec{X}_{C B} \\
\vec{X}_{D B}
\end{array}\right]
$$

The adjustment of network was done alongside the processing earlier mentioned using Hi-target Geomatics Office. This is provided for in the software and output can be in Microsoft Excel file format.

Table 3 shows the baselines IDs, lengths, uncorrected baselines, baseline residuals, correction to uncorrected baselines, the final change or difference in coordinates and heights.

Table 3: Baseline lengths and residuals

\begin{tabular}{|c|c|c|c|c|c|c|c|c|c|c|c|c|c|c|}
\hline \multicolumn{2}{|c|}{ Baseline } & \multirow{2}{*}{ 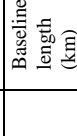 } & \multicolumn{3}{|c|}{ Uncorrected Baseline } & \multicolumn{3}{|c|}{ Baseline Residual } & \multicolumn{3}{|c|}{$\begin{array}{l}\text { Corrected Baseline } \\
\text { (m) }\end{array}$} & \multirow{2}{*}{$\begin{array}{c}\text { Easting (m) } \\
\mathrm{X}\end{array}$} & \multirow{2}{*}{$\begin{array}{c}\begin{array}{c}\text { Northing } \\
(\mathrm{m})\end{array} \\
\mathrm{Y}\end{array}$} & \multirow{2}{*}{ 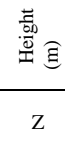 } \\
\hline From & To & & $\Delta \mathrm{X}(\mathrm{m})$ & $\Delta \mathrm{Y}(\mathrm{m})$ & $\Delta \mathrm{Z}(\mathrm{m})$ & $\mathrm{Vx}(\mathrm{m})$ & $\mathrm{Vy}(\mathrm{m})$ & $\mathrm{Vz}(\mathrm{m})$ & $\Delta \mathrm{X}$ & $\Delta \mathrm{Y}$ & $\Delta \mathrm{Z}$ & & & \\
\hline \multicolumn{2}{|c|}{ XSU92 (control) } & 0 & 0 & 0 & 0 & 0 & 0 & 0 & 0 & 0 & 0 & $\begin{array}{l}356733.378 \\
8\end{array}$ & $\begin{array}{l}244420.305 \\
1\end{array}$ & 103.92 \\
\hline $\begin{array}{c}\text { BEM_1 } \\
000\end{array}$ & XSU92 & 12.2 & 5290.0024 & 19984.1984 & -70657.6415 & 0.0045 & 0.0061 & 0.0033 & 5289.9979 & 19984.1923 & -70657.6448 & $\begin{array}{l}622956.590 \\
1 \\
\end{array}$ & $\begin{array}{l}376244.813 \\
8 \\
\end{array}$ & 54.36 \\
\hline $\begin{array}{c}\text { GPS- } \\
\text { ITER_0 } \\
1\end{array}$ & $\begin{array}{c}\text { BEM_1 } \\
00\end{array}$ & 86.6 & -1531.1362 & 913.3610 & 13501.4345 & -0.0570 & -0.0022 & -0.0009 & -1531.0792 & 913.3632 & 13501.4354 & $\begin{array}{l}642940.801 \\
7\end{array}$ & $\begin{array}{l}364031.543 \\
1\end{array}$ & 24.36 \\
\hline $\begin{array}{c}\text { NP- } \\
\text { Ww01 }\end{array}$ & $\begin{array}{c}\text { NP- } \\
\text { WW02 }\end{array}$ & 13.6 & -6599.4692 & -7838.9332 & 71555.8851 & 0.0014 & -0.0007 & 0.0085 & -6599.4706 & -7838.9325 & 71555.8766 & $\begin{array}{l}630795.540 \\
0 \\
\end{array}$ & $\begin{array}{l}363978.293 \\
1 \\
\end{array}$ & 21.27 \\
\hline $\begin{array}{c}\text { NP- } \\
\text { Ww02 }\end{array}$ & $\begin{array}{c}\text { NP- } \\
\text { WW03 }\end{array}$ & 12.3 & -1309.5621 & 12145.2226 & 898.1741 & -0.0008 & -0.0002 & 0.0227 & -1309.5613 & 12145.2228 & 898.1514 & $\begin{array}{l}630742.566 \\
3 \\
\end{array}$ & $\begin{array}{l}363915.871 \\
5\end{array}$ & 21.07 \\
\hline $\begin{array}{c}\text { NP- } \\
\text { Ww03 }\end{array}$ & $\begin{array}{c}\text { GPS- } \\
\text { ITER_0 } \\
1 \\
\end{array}$ & 12.4 & -8130.6310 & -6925.5537 & 85057.3321 & 0.0014 & -0.0007 & -0.0025 & -8130.6324 & -6925.5530 & 85057.3346 & $\begin{array}{l}630680.512 \\
9\end{array}$ & $\begin{array}{l}357763.331 \\
5\end{array}$ & 21.29 \\
\hline $\begin{array}{l}\text { GPS- } \\
\text { ITER_0 } \\
1\end{array}$ & XSU92 & 73.6 & -6605.0034 & -7785.9560 & 71560.3778 & 0.0006 & 0.0001 & 0.0002 & -6605.0040 & -7785.9561 & 71560.3776 & $\begin{array}{l}622956.590 \\
1\end{array}$ & $\begin{array}{l}356733.378 \\
8\end{array}$ & 103.92 \\
\hline
\end{tabular}

The accuracy standard for each baseline can be derived from linear accuracy relationship as follows:

$1:\left\{\left[V x^{2}+V y^{2}\right]^{1 / 2} / l_{a c}\right\}$

$V_{x}$ and $V_{y}$ are as presented in Table 4 and $l_{a c}$ is the baseline length.

By multiplying Equation (17) by 1,000,000 gives the accuracy in parts per million (ppm).

$1:\left\{\left[V z^{2}\right]^{1 / 2} / l_{a c}\right\}$

$V_{z}$ are also represented in Table 5 and $l_{a c}$ represents the base line length. By multiplying Equation (18) by $1,000,000$ gives the accuracy in parts per million (ppm).

Table4: Horizontal accuracy

\begin{tabular}{|l|l|l|l|l|l|l|c|c|}
\hline \multicolumn{2}{|c|}{ Baseline } & & \multicolumn{7}{c|}{ Baseline Residual } \\
\hline From & To & Vx (m) & Vy (m) & Length (m) & Linear Accuracy & $\begin{array}{l}\text { Std. } \\
\text { Dev_N } \\
(\mathrm{mm})\end{array}$ & $\begin{array}{l}\text { Std. } \\
\text { Dev_E } \\
(\mathrm{mm})\end{array}$ & ppm \\
\hline XSU92 & BEM_1000 & 0.0045 & 0.0061 & 12248.558 & 1615854.128 & 13.4 & 17.5 & 2 \\
\hline BEM_1000 & NP-WW01 & -0.0570 & -0.0022 & 86562.033 & 1517502.275 & 6.2 & 11.7 & 0 \\
\hline NP-WW01 & NP-WW02 & 0.0014 & -0.0007 & 13618.621 & 8700617.805 & 9.9 & 15.1 & 9 \\
\hline NP-WW02 & NP-WW03 & -0.0008 & -0.0002 & 12301.988 & 14918351.744 & 10.0 & 15.2 & 15 \\
\hline NP-WW03 & $\begin{array}{l}\text { GPS- } \\
\text { ITER_01 }\end{array}$ & 0.0014 & -0.0007 & 12364.648 & 7899483.842 & 10.0 & 15.3 & 8 \\
\hline GPS-ITER_01 & XSU92 & 0.0006 & 0.0001 & 73619.617 & 121029904.806 & 0.0 & 0.0 & 121 \\
\hline
\end{tabular}


Table 4 shows the stations horizontal coordinates residuals, baseline lengths as well as linear accuracy in parts per million. The maximum parts per million accuracy obtained in horizontal was 121 while the minimum was 0.1 .

Table 5: Vertical accuracy

\begin{tabular}{|l|l|l|l|l|c|c|}
\hline \multicolumn{1}{|c|}{ From } & \multicolumn{1}{|c|}{ To } & Vz (m) & Length (m) & Vertical Accuracy & $\begin{array}{c}\text { Std. } \\
\text { Dev_U } \\
(\mathrm{mm})\end{array}$ & ppm \\
\hline XSU92 & BEM_1000 & 0.0033 & 12248.558 & 3711684.242 & 44.8 & 4 \\
\hline BEM_1000 & NP-WW01 & -0.0009 & 86562.033 & 96180036.667 & 27.1 & 96 \\
\hline NP-WW01 & NP-WW02 & 0.0085 & 13618.621 & 1602190.706 & 34.9 & 2 \\
\hline NP-WW02 & NP-WW03 & 0.0227 & 12301.988 & 541937.797 & 35.0 & 1 \\
\hline NP-WW03 & $\begin{array}{l}\text { GPS- } \\
\text { ITER_01 }\end{array}$ & -0.0025 & 12364.648 & 4945859.200 & 35.1 & 5 \\
\hline GPS-ITER_01 & XSU92 & 0.0002 & 73619.617 & 368098085.000 & 0.0 & 368 \\
\hline
\end{tabular}

Table 5 shows the station vertical coordinate residuals, baseline lengths as well as vertical accuracy in part per million. The maximum parts per million accuracy obtained in vertical was 368 while the minimum was 1.

\subsection{Relative accuracy standard for national surveys in Nigeria}

The relative accuracy standard for national surveys as specified by Surveyor Council of Nigeria (SURCON) (2007) for horizontal and vertical control was compared with the accuracy standard obtained and the results are presented in Tables 6 and 7.

Table 6: Horizontal accuracy standard

\begin{tabular}{|l|c|c|c|c|c|c|}
\hline \multicolumn{1}{|c|}{ Baseline } & $\begin{array}{c}\text { Class } \\
\text { Description }\end{array}$ & $\begin{array}{c}\text { Allowable linear } \\
\text { misclosure } \\
\frac{\sqrt{\Delta x^{2}+\Delta y^{2}}}{\sum L}\end{array}$ & Dist.(m) & $\Delta x$ & $\Delta y$ & $\begin{array}{c}\text { Obtained linear } \\
\text { misclosure } \\
\frac{\sqrt{\Delta x^{2}+\Delta y^{2}}}{\sum L}\end{array}$ \\
\hline XSU92 & First Order & $1: 100,000$ & 12248.558 & 0.0045 & 0.0061 & $1: 161,585$ \\
\hline BEM_1000 & First Order & $1: 100,000$ & 86562.033 & -0.0570 & -0.0022 & $1: 151,750$ \\
\hline NP-WW01 & First Order & $1: 100,000$ & 13618.621 & 0.0014 & -0.0007 & $1: 870,062$ \\
\hline NP-WW02 & First Order & $1: 100,000$ & 12301.988 & -0.0008 & -0.0002 & $1: 149,184$ \\
\hline NP-WW03 & First Order & $1: 100,000$ & 12364.648 & 0.0014 & -0.0007 & $1: 789,948$ \\
\hline GPS-ITER_01 & First Order & $1: 100,000$ & 73619.617 & 0.0006 & 0.0001 & $1: 121,029$ \\
\hline
\end{tabular}

Table 7: Vertical accuracy standard

\begin{tabular}{|l|c|c|c|c|c|}
\hline \multicolumn{1}{|c|}{ Baseline } & $\begin{array}{c}\text { Distance } \\
(\mathrm{d})(\mathrm{km})\end{array}$ & $\begin{array}{c}\text { St. Dev. of elevation } \\
\text { diff. }(\mathrm{S})(\mathrm{mm})\end{array}$ & $\begin{array}{c}\text { Misclosure } \\
(\mathrm{b})=(\mathrm{S} / \sqrt{\mathrm{d}})=(\mathrm{mm}) / \\
\sqrt{\mathrm{km}})\end{array}$ & Class & Remark \\
\hline XSU92 & 12.2 & 0.0 & 0.0 & II & ok \\
\hline BEM_1000 & 86.6 & 44.8 & 4.81 & II & ok \\
\hline NP-WW01 & 0.05 & 27.1 & 121.20 & II & ok \\
\hline NP-WW02 & 0.06 & 34.9 & 142.48 & II & ok \\
\hline NP-WW03 & 0.12 & 35.0 & 101.04 & II & ok \\
\hline GPS-ITER_01 & 73.6 & 35.1 & 40.91 & II & ok \\
\hline
\end{tabular}

\subsection{Data Analysis, Results and Map Production}

\subsection{Comparison of adjusted data with fixed controls}

Hi-target post processing software allows network adjustment to be performed, first by holding the control point XSU92 fixed which is the one referenced to Lagos datum, again by using the Lower 
Low Water datum at Warri and repeating the process. The outcome of this process is presented in Figure 2.

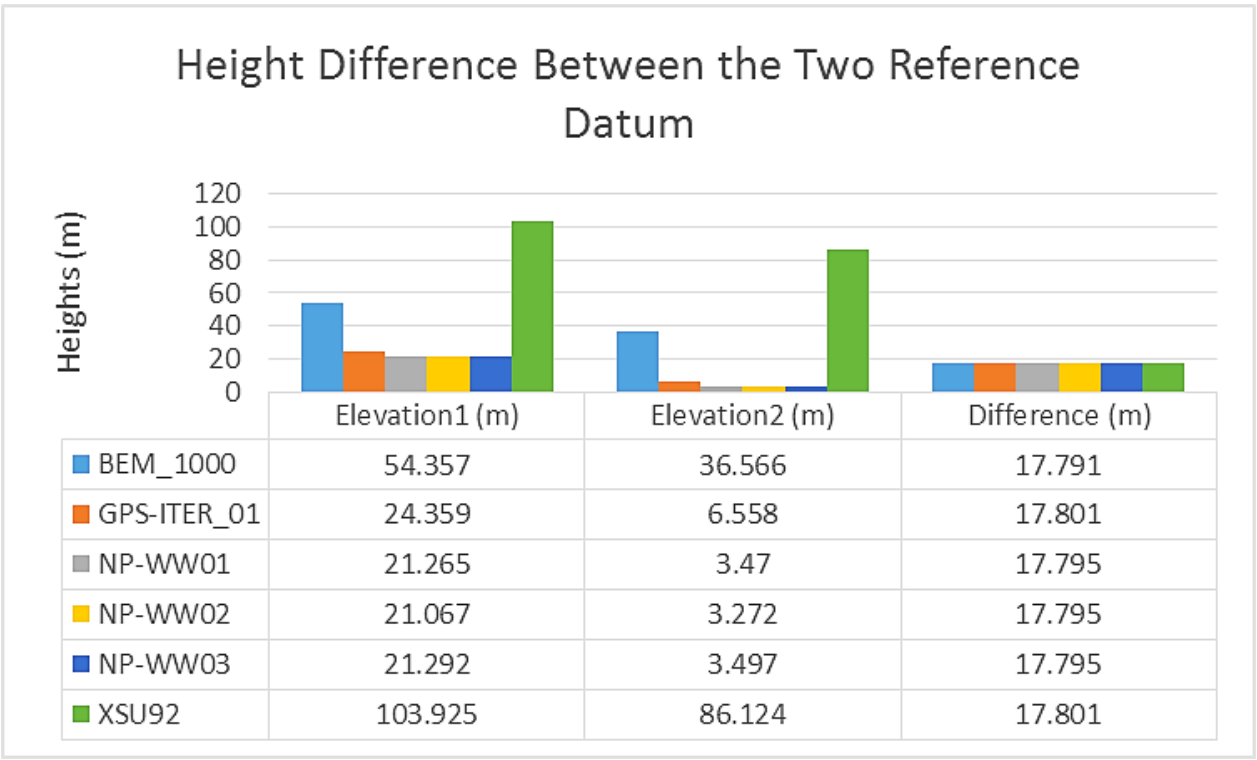

Figure 2: Difference in heights between the two reference points

From Figure 2, Elevation 1 is Lagos datum reference, while Elevation 2 is for Warri Lower Low Water reference. It also shows the differences obtained when the two reference systems are compared. The differences maintain what can be seen as almost constant values for all the respective points considered. A mean of $17.79 \mathrm{~m}$ was obtained when the heights were averaged given rise to the constant factor determined from this work.

\subsection{Stacking a contour map over a 3D surface map}

Plotting of a contour map can be done over a 3D surface map using the following procedure for stacking maps in surfer golden software, (2011) clicking help from the software window and search. Usually a contour map is stacked over a 3D surface of the same grid file, but you can also stack different grid files one over another. If different grid files are used for stacking, the $\mathrm{X}$ and $\mathrm{Y}$ coordinates for both the grid files should be similar.

Figure 3 is a stack map of the study area at a scale of 1:5000 at contour intervals of $5 \mathrm{~m}$ with the highest showing a height of $90 \mathrm{~m}$. The 3D model of the area represented was also shown. The reference was to the Lagos Datum defined by the control in Benin, Edo State.

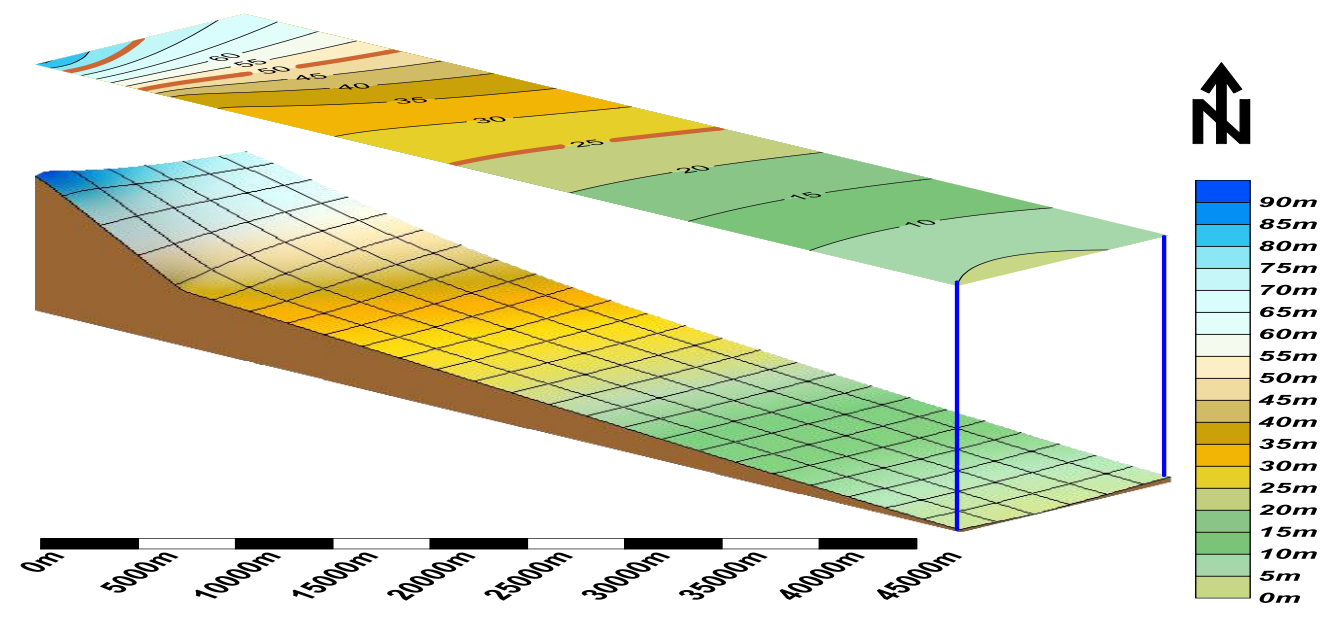

Figure 3: Stack maps of the study area with reference to XSU92. 
Figure 4 is a stack map of the study area at a scale of 1:5000 at contour interval of $5 \mathrm{~m}$ with the highest showing a height of $90 \mathrm{~m}$. The 3D model of the area represented was also shown. The reference is to the Lower Low Water at Warri Delta State. The two stack maps represented in Figures 3 and 4 are similar pictorially for the two data set represented.

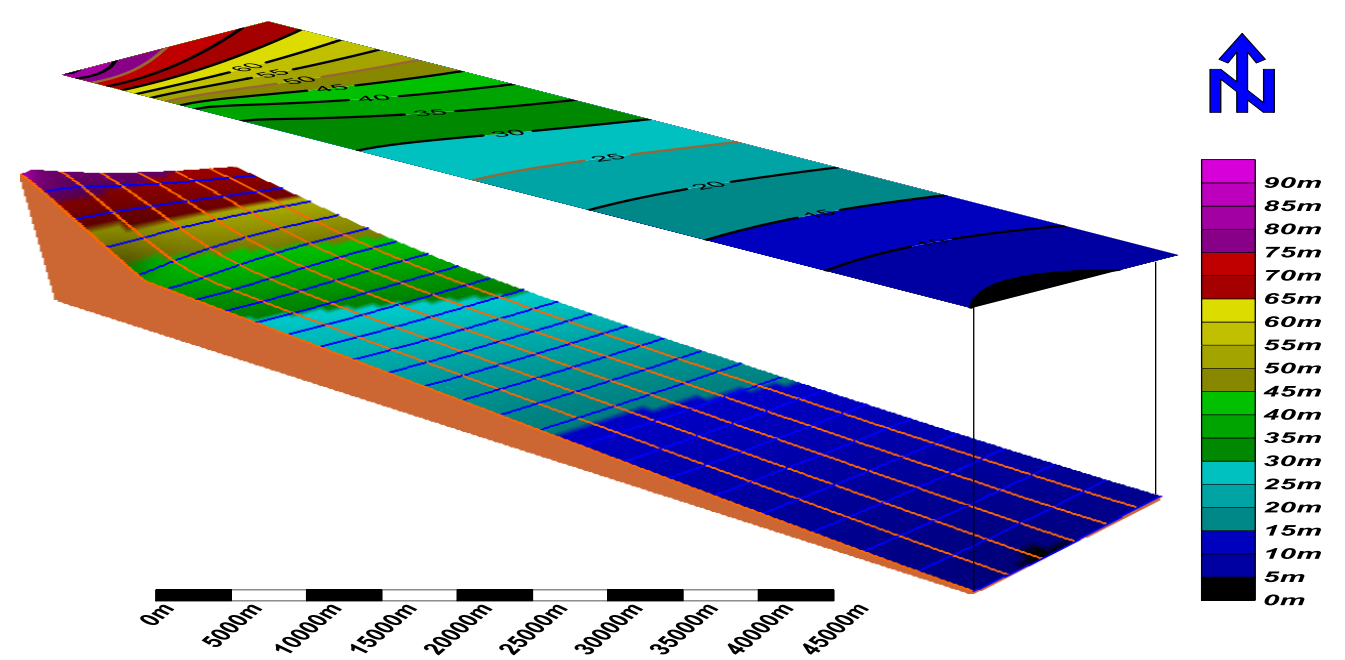

Figure 4: Stack maps of the study area with reference to NP-WW01

\subsection{Conclusion/ Recommendations}

In this study, a conversion factor for height has been determined by taking the mean of the differences in heights as shown in Figure 1. Horizontal and Vertical accuracy have been evaluated as well as the positional accuracy and standard for GNSS first and second order geodetic coordinates as specified by Surveyors Council of Nigeria (SURCON).

Due to the fact that no satellites under horizon are available, GPS receivers can only receive signals from satellites above ground. This results in a poor geometry for fixing the height component in GPS measurements. In contrast, the horizontal components are fixed by satellites from different azimuths of the sky. It is therefore worthy of note that the VDOP value is always higher than the HDOP value and the accuracy of vertical component is often less precise than horizontal one by 2 to 3 times or even more depending on the satellite geometry (Choi et al., 2007).

Throughout the study, a confidence level of $10.00 \sigma$ was maintained, significance level for $\tau$ test is at $1.00 \%$ and ratio of standard error of unit weight is 2.7803 . The accuracy of the heights is not as good as that of the horizontal. This is probably due to errors associated with Satellite. For example satellite Constellation, tropospheric delay, Phase Centre Variation (PCV) and Offset, Multipath, Geoidellipsoid separation accuracy etc. as can be observed from Tables 4 and 5 considering the standard deviation in $\mathrm{E}, \mathrm{N}$ and $\mathrm{H}$ respectively. The following conclusions have been made:

i. While working in Benin with reference to the XSU92 and NP-WW01 controls, a value of $17.79 \mathrm{~m}$ can be an alternative constant to swap between the two reference datum for data collection or as a means of check on observations carried out in that region

ii. The accuracy standard for $1^{\text {st }}$ order control is $1: 100,000$. The obtained standard proves to be better giving an indication that the GNSS equipment deploy for this study is of high accuracy

iii. A class II standard accuracy was obtained for vertical standard accuracy

iv. The maximum parts per million accuracy obtained in horizontal was 121 while the minimum was 0 as shown in Table 4

v. For vertical, the maximum parts per million accuracy obtained was 368 while the minimum was 1 as presented in Table 5 . 


\section{References}

Badejo, O.T., Olaleye, J.B. and Alademomi, A.S. (2014). Tidal characteristics and sounding datum variation in Lagos State. Department of Surveying and Geoinformatics, University of Lagos. ISSN 2319-9725.

British Oceanic Data Centre, (2011). GLOSS Station Handbook. Station information sheet.

Choi, D. C. T., Wong, J. Y. K. and Chan, B. S. B. (2007). Investigation on GPS Heighting Accuracy with the use of Hong Kong Satellite Positioning Reference Station Network (Sat Ref) Strategic Integration of Surveying Services. FIG Working Week 2007 Hong Kong SAR, China, 13-17 May 2007.

Civil Engineering Document (CED) (2012). Sources of Errors in GPS and their Corrections Available at: https://www.aboutcivil.org/sources-of-errors-in-gps.html

Ebong et al. and AVN International (1991). Lagos 1955 height. Available at: https://epsg.io/5796

Ehigiator, M. O., Oladosu, S. O. and Ehigiator-Irughe, R. (2017). Densification of (GNSS) Control Points for Cadastral and Mapping Purposes. Nigerian Journal of Environmental Sciences and Technology (NIJEST), 1(2), pp. 287-298.

Geoffrey Blewitt (1997). Basics of the GPS Technique. Department of Geomatics, University of Newcastle, Newcastle upon Tyne, NE1 7RU, United Kingdom.

Georgiadou, P.Y., Knippers, R.A., Kraak, M.J., Sun, Y., Weir, M.J.C. et al. (2001). Principles of geographic information systems (Chapter 4.2 on spatial referencing), 2nd edition, ITC Educational Textbook, ITC, Enschede, 2001.

GPS and GNSS for Geospatial Professionals (2015). Pennstate College of Earth and Mineral Sciences Available at: https://www.e-education.psu.edu/geog862/node/1858 [Accessed 08 March. 2018]

Leica Geosystems User Manual (2000). General Guide to Static and Rapid-Static. Copyright Leica Geosystems AG, Heerbrugg, Switzerland 2000 Printed in Switzerland.

Michael, P. V. (2005). Carrier Phase Techniques. Available at: https://cs.stanford.edu/ woodward/papers/cp_dgps.pdf [Accessed 28 June, 2018].

Pete Bettinger and Krista Merry (2012). Static Horizontal Positions Determined With a ConsumerGrade GNSS Receiver: One Assessment of the Number of Fixes Necessary. Croat. j for. Eng. 33, pp. 149-157.

Pirti, A. (2005). Using GPS near the forest and quality control. Survey Review 38(298), pp. 286-299.

Royal Institution of Chartered Surveyors (RICS) (2010). Guidelines for the use of GPS in land surveying. Published by the Royal Institution of Chartered Surveyors (RICS) ISBN 978184219607 6.

Shell Petroleum Development Company (2010). The derived datum shift parameters for conversion between WGS 84 and Minna datum.

Standard for New Zealand Geodetic Datum (SNZGD) (2000). Equations used for datum transformations online resource Available at: https://www.linz.govt.nz/regulatory/25002 [Accessed 08 March. 2018].

SURCON (2007). Specifications for Geodetic Surveys in Nigeria. (Surveyors Council of Nigeria) GPS Surveys Specifications, pp. 44-46. 
Tide Tables and Solunar Charts for Warri (2013). High tides and low tides, surf reports, sun and moon rising and setting times, lunar phase, fish activity and weather. Available at: http://www.tides4fishing.com/af/nigeria/warri [Accessed 08 March. 2018].

Uzodinma, V. N. (2005). VLBI, SLR and GPS Data in the Nigerian Primary Triangulation Network: What Benefits to Future Research and the National Economy? In: Proceedings of the 1st International Workshop on Geodesy and Geodynamics, Toro, Nigeria, 10th - 11th February 2005. 